\title{
Fabrication of TiNi Powder by Mechanical Alloying and Shape Memory Characteristics of the Sintered Alloy*1
}

\author{
Akira Terayama $^{1, * 2}$, Hideki Kyogoku ${ }^{2}$, Masaru Sakamura ${ }^{3}$ and Shinichiro Komatsu ${ }^{2}$ \\ ${ }^{1}$ Graduate Student, Kinki University, Higashihiroshima 739-2116, Japan \\ ${ }^{2}$ Department of Mechanical Engineering, School of Engineering, Kinki University, Higashihiroshima 739-2116, Japan \\ ${ }^{3}$ Tobu Industrial Research Institute of Hiroshima Prefecture, Fukuyama 721-0974, Japan
}

This paper presents the fabrication condition of TiNi alloy powder by mechanical alloying and shape memory characteristics of the sintered alloy. The effect of mechanical alloying condition on the characteristics of mechanically alloyed powder (MA powder) was investigated. Also, the difference in sintering behavior between the MA powder and the elementally mixed powders by V-blender and the shape memory characteristics of the sintered alloys were also examined. The MA powder was fabricated by milling using a planetary ball mill in a rotational speed between 200 and $500 \mathrm{~min}^{-1}$ for various milling times in an atmosphere of Ar gas. These two types of powders prepared in different processes were sintered using a pulse-current pressure sintering equipment at various sintering temperatures. The powder agglomerated and its particle size became larger with an increase in milling time. The mixture of $\mathrm{Ti}$ and Ni powders changed into an amorphous state by processing for $3.6 \mathrm{ks}$ over $300 \mathrm{~min}^{-1}$. The sintered alloy of the MA powder showed more uniform phase of TiNi than that of the elementally mixed powders sintered in a same manner, however, the former showed a lower density than the latter due to a larger particle size of the MA powder of before-sintering. It was found from the measurement of the transformation temperature of the sintered alloy of the MA powder using DSC that the alloy has shape memory characteristics, and the transformation temperatures of the alloy are higher than those of the alloy of the elementally mixed powders due to waste of $\mathrm{Ni}$ powder.

(Received August 25, 2005; Accepted November 7, 2005; Published March 15, 2006)

Keywords: TiNi shape memory alloy, mechanical alloying, sintering, density, shape memory characteristics

\section{Introduction}

TiNi shape memory alloy is one of the essential functional materials in the field of smart materials which need functions of a sensor and an actuator because the alloy has a unique characteristic that the deformed alloy returns to the original shape by heating. The alloy is commonly fabricated by a casting-cold working process, but because of some crucial problems of segregation and contamination in the casting process, the manufacturing process of wires and plates using ingots fabricated by combustion synthesis has been in practical use. ${ }^{1)}$ Recently, the authors ${ }^{2-5)}$ have investigated the fabrication of the $\mathrm{Ti}-\mathrm{Ni}$ shape memory alloy using elemental $\mathrm{Ti}$ and $\mathrm{Ni}$ powders by means of a pulse-current pressure sintering equipment and have reported that the alloys obtained show superior shape memory characteristics which are comparable to those of the wrought material. However, since the sintering of elementally mixed powders by a V-blender (V-blended powder) resulted in inhomogeneous microstructure in the sintered alloy, it was found that the alloys fabricated have some problems in fatigue properties and control of elements of the alloy. Therefore, the application of the TiNi alloy powder is considered to be quite effective in fabrication of the sintered compacts having homogeneous microstructure, but the utilization of gas atomizing process for producing the alloy powder causes not only high cost but also difficulty of changing the composition of the alloy. By replacing this process with mechanical alloying (MA) process, it is fairly easy to

\footnotetext{
${ }^{* 1}$ This Paper was Originally Published in Japanese in J. Jpn. Inst. Met. 69 (2005) 523-529.

${ }^{* 2}$ Graduate Student, Kinki University, Present address: Seibu Industrial Research Institute of Hiroshima Prefecture, Kure 737-0004
}

fabricate the alloy powder and change the composition of the alloy as well. There are some reports ${ }^{6-9)}$ on the fabrication of Ti-Ni shape memory alloy powder by MA process, but the full MA conditions, the mechanical and shape memory characteristics of the sintered alloy have not been examined enough.

In this research, we investigated the fabrication conditions, such as process control agents, rotational speed and milling time, which are significant to fabricate the $\mathrm{Ti}-\mathrm{Ni}$ shape memory alloy powder by MA process. Also, we examined the powder characteristics and the microstructures and shape memory characteristics of the sintered alloy of the MA powder.

\section{Experimental Procedure}

Gas-atomized Ti and carbonyl Ni powders, which are 24 and $6.2 \mu \mathrm{m}$ in mean particle diameter respectively, were used in this research. The chemical compositions of these powders are listed in Table 1 . These powders were mixed by a Vblender at the composition of $\mathrm{Ti}-50.2$ at $\% \mathrm{Ni}$ and then milled by means of a planetary ball mill. The ball to powder weight ratio was 5:1. The powder mixture was milled together with

Table 1 Mean particle diameters and chemical compositions of Ti and Ni powders.

\begin{tabular}{llllllll}
\hline & & \multirow{6}{c}{$\begin{array}{c}\text { Mean particle } \\
\text { Piameter } \\
(\mu \mathrm{m})\end{array}$} & \multicolumn{5}{c}{ Chemical compositions (mass\%) } \\
\cline { 5 - 8 } & & $\mathrm{Fe}$ & $\mathrm{O}$ & $\mathrm{N}$ & $\mathrm{H}$ & $\mathrm{C}$ \\
\hline $\mathrm{Ti}$ & $\begin{array}{l}\text { Gas-atomized } \\
\text { powder }\end{array}$ & 24 & 0.053 & 0.13 & 0.005 & 0.007 & 0.009 \\
\hline $\mathrm{Ni}$ & $\begin{array}{l}\text { Carbonyl } \\
\text { powder }\end{array}$ & 6.2 & 0.003 & 0.069 & - & - & 0.078 \\
\hline
\end{tabular}


stainless steel balls in an atmosphere of Ar gas at a rotational speed between 200 and $500 \mathrm{~min}^{-1}$ for a milling time between 3.6 and $360 \mathrm{ks}$. The mechanically alloyed powder (MA powder) obtained was filled into a graphite die and sintered by means of a pulse-current pressure sintering equipment. The sintering was performed for a time of $1.8 \mathrm{ks}$ at a temperature between 1123 and $1223 \mathrm{~K}$ under a load of $24.5 \mathrm{kN}$ after pre-treatment of pulse current (current: $500 \mathrm{~A}$, interval: $30 \mathrm{~ms}$, duration time: $30 \mathrm{~s}$ ).

X-ray diffraction (XRD) analysis, SEM observation, particle size measurement and chemical analysis of the MA powder were carried out, and density measurement, optical microscopic observation, XRD analysis and DSC analysis of the sintered alloys were also performed.

\section{Results and Discussions}

\subsection{Fabrication conditions}

It is of vital importance for mechanical alloying to select properly the factors, such as (1) process control agents (PCA) which are used to prevent from excessive cold welding the powder onto a wall of vial and milling balls and agglomeration of powder, (2) ball to powder weight ratio, (3) rotational speed, (4) milling time, and (5) atmosphere. In this research, the ball to powder weight ratio was fixed on 5:1 and Ar gas was selected as an atmosphere in consideration of the previous reports. ${ }^{10,11)}$ The optimum fabrication conditions of process control agent, rotational speed and milling time were investigated experimentally.

It is significant to avoid carburization and oxidation of titanium during milling process because titanium has high reactivity to carbon and oxygen. It has been reported ${ }^{10-12)}$ that the contamination in mechanically alloyed powder is carbon and oxygen from process control agents, such as stearic acid, methanol and so on, as well as an atmosphere. In this research, we employed water and methanol as process control agents and the former contains no carbon, being different from organic agents, while the latter is commonly used well as a process control agent. The effects of these process control agents on the recovery percentage of the MA powder and the contamination of carbon and oxygen in the MA powder were examined.

The effect of the addition of process control agent on the recovery percentage was examined. In the case of every

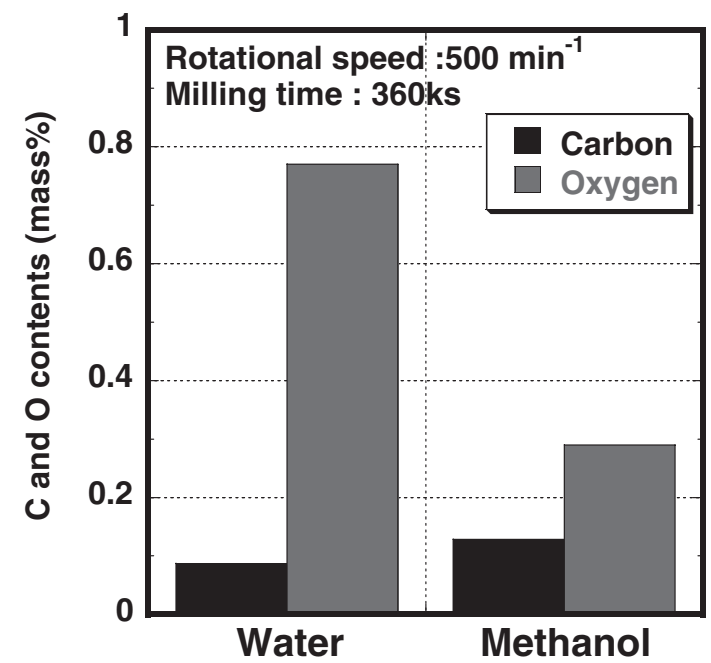

Fig. 1 Effect of process control agent on carbon and oxygen contents of the MA powder.

rotational speed and milling time, the addition of process control agent results in an increase of approximately $20 \%$ in the recovery percentage. Thus the addition of process control agent is effective to prevent agglomeration of powder. The effect of process control agents on the contamination, especially carbon and oxygen, of the MA powder was investigated. Figure 1 shows the effect of process control agents on carbon and oxygen contents of the powder mechanically alloyed at $500 \mathrm{~min}^{-1}$ for $360 \mathrm{ks}$. The carbon contents are 0.08 and 0.13 mass $\%$ in the cases of water and methanol respectively, and the latter is slightly higher than the former. As already reported, ${ }^{12)}$ this difference in carbon content is due to the contamination of carbon of methanol during MA process. On the other hand, the oxygen contents are 0.76 and 0.29 mass $\%$ in the cases of water and methanol respectively, and the former is much higher than the latter. This difference in oxygen content is also due to the contamination of oxygen of water. Since the ductility of the alloy deteriorates abruptly more than 0.3 mass $\%$ in oxygen content, ${ }^{13)}$ the increase in oxygen content is harmful to the shape memory characteristics of the alloy. The authors ${ }^{2-5}$ ) have already reported that the sintered alloy of the elementally mixed powders shows superior shape memory charac- (a) Water

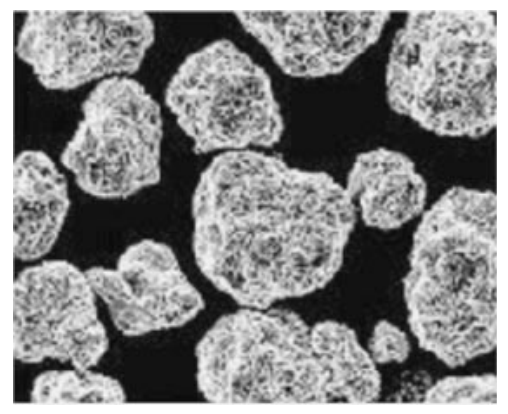

(b) Methanol

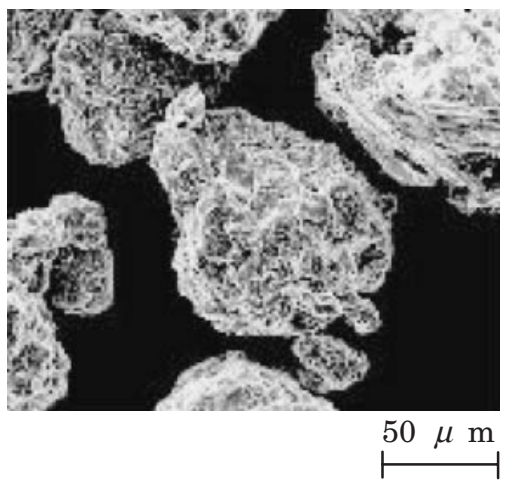

Fig. 2 SEM micrographs of the powders mechanically alloyed using water and methanol as process control agents. 
(a) Water

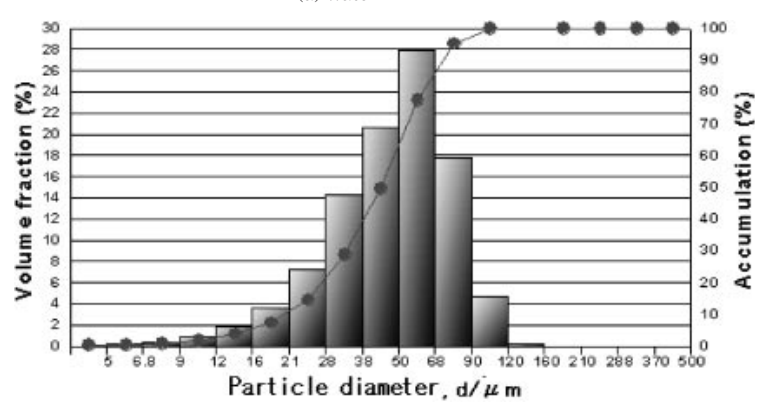

(b) Methanol

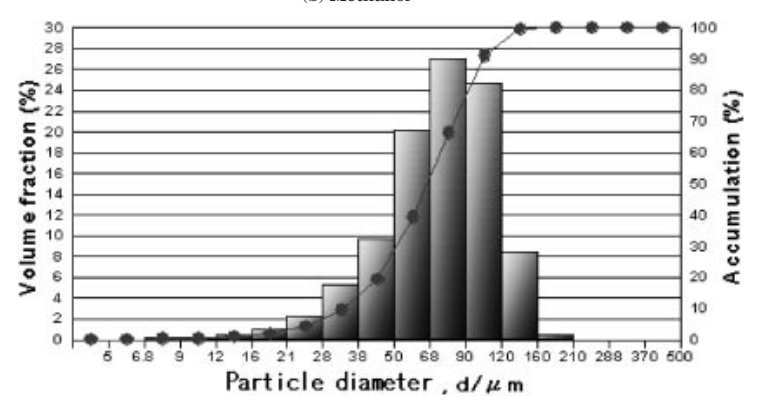

Fig. 3 Distribution in particle size of the MA powder.

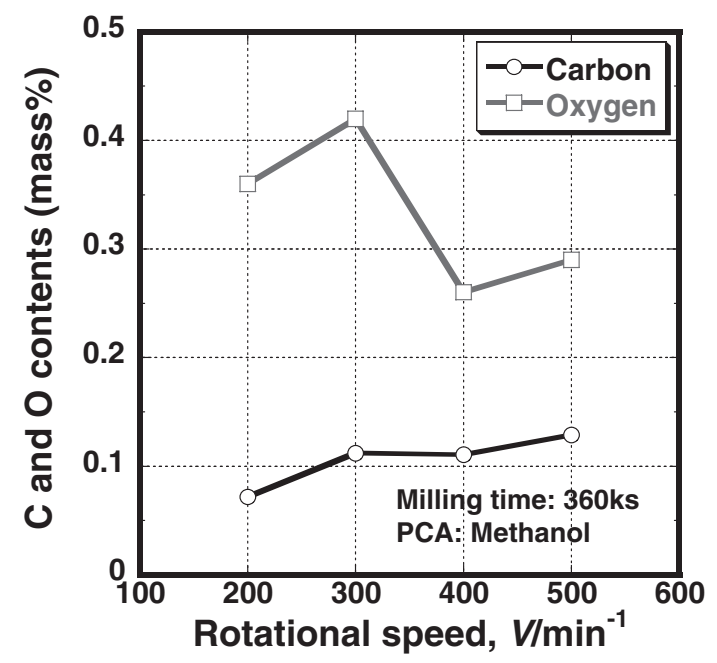

Fig. 4 Effect of rotational speed on carbon and oxygen contents of the MA powder.

teristics in contents less than 0.1 mass $\% \mathrm{C}$ and less than 0.2 mass $\%$ O. But the carbon and oxygen contents of the sintered alloy of the MA powder are considerably higher.

The effects of process control agents on the shape of the MA powder and the distribution in particle size were examined. Figure 2 shows SEM micrographs of the powders mechanically alloyed at $500 \mathrm{~min}^{-1}$ for $360 \mathrm{ks}$ using water and methanol as process control agents. In the case of methanol, the shape of the powder is irregular, while in the case of water, the shape of the powder is near spherical and the width of distribution in particle size becomes narrower. The distribution in particle size of the MA powder is demonstrated in Fig. 3. It is found from this result that the mean particle sizes are 60 and $45 \mu \mathrm{m}$ in the cases of methanol and water respectively, and the mean particle size of the latter is (a) Carbon content

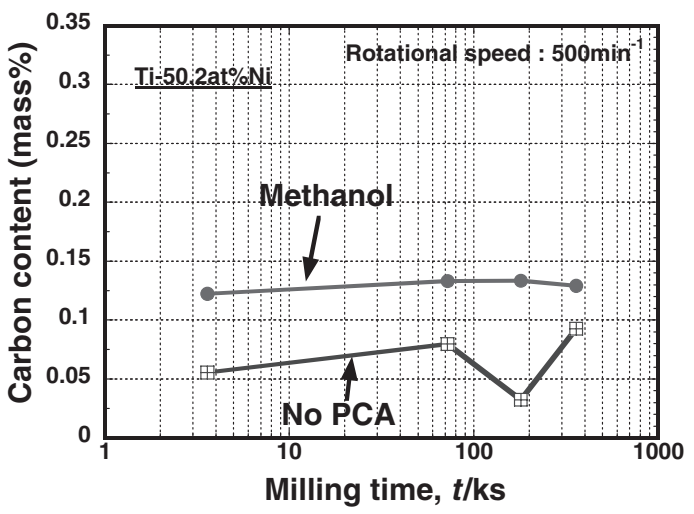

(b) Oxygen content

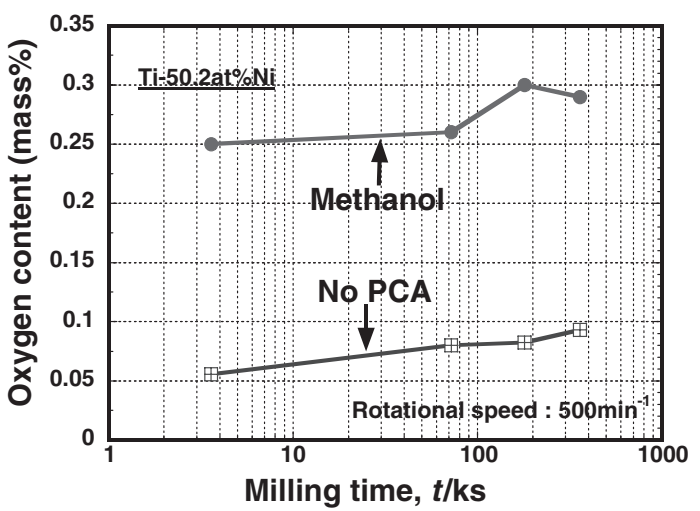

Fig. 5 Effect of milling time on carbon and oxygen contents of the MA powder.

smaller and the shape of the latter is more spherical. Also the shape and the distribution in particle size of the MA powder without process control agent were similar to those of the MA powder using water.

The effect of rotational speed on carbon and oxygen contents of the powder mechanically alloyed for $360 \mathrm{ks}$ using methanol as a process control agent are shown in Fig. 4. The carbon content shows a slight increasing tendency with an increase in rotational speed. On the other hand, the oxygen content of the powder mechanically alloyed at lower rotational speeds of 200 and $300 \mathrm{~min}^{-1}$ is higher than that of the powder at higher rotational speeds of 400 and $500 \mathrm{~min}^{-1}$. It is found that the rotational speed slightly affects the carbon content of the MA powder, but it greatly affects the oxygen content of the MA powder, that is, the higher rotational speed gives better shape memory characteristics of the sintered compacts than the lower one.

Figure 5 shows the effect of milling time on carbon and oxygen contents of the MA powder. The oxygen content shows a slight increasing tendency with an increase in milling time, while the carbon content changes with milling time. Also the carbon and oxygen contents of the MA powder without a process control agent are less than those of the MA powder using methanol in whole milling time. Thus it was found from these results that the addition of a process control agent improves the recovery percentage of the MA powder, but increases the carbon and oxygen contents. 
(a) $36 \mathrm{ks}$

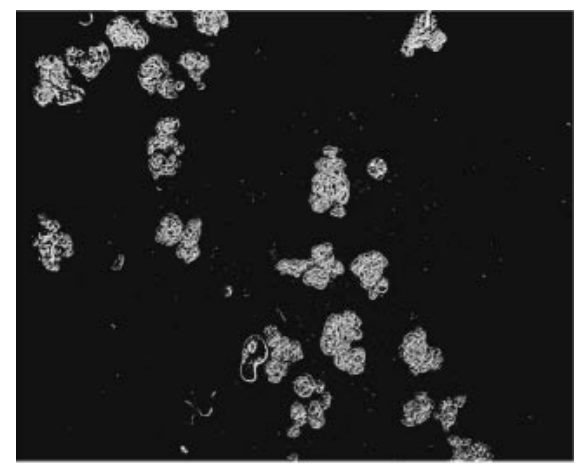

(c) $180 \mathrm{ks}$

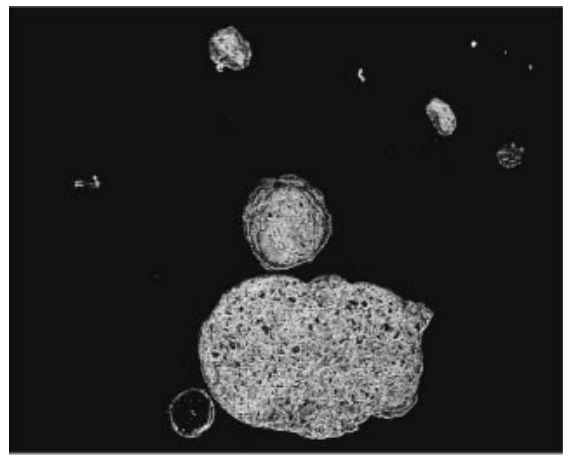

(b) $72 \mathrm{ks}$

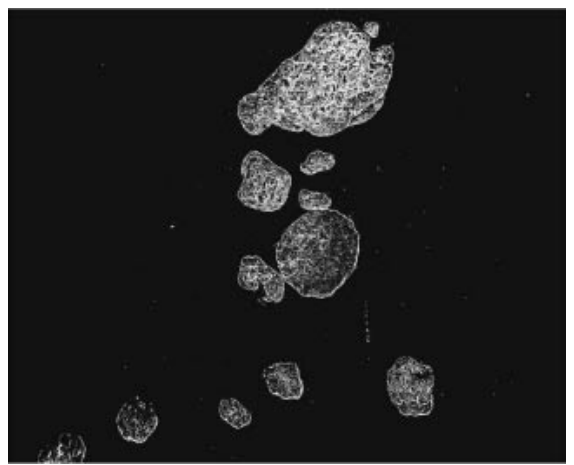

(d) $360 \mathrm{ks}$

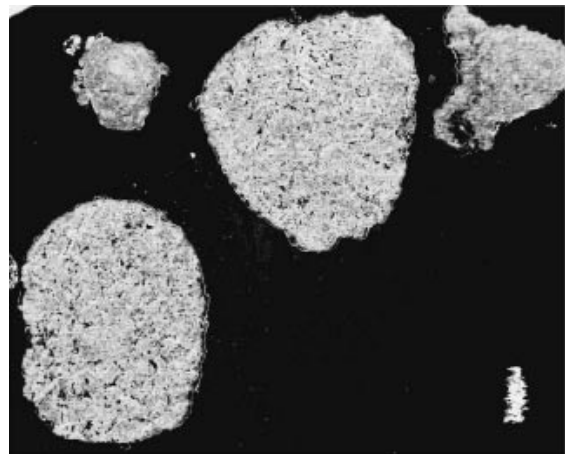

$1 \mathrm{~mm}$

Fig. 6 Change in particle size of the MA powder with milling time at $200 \mathrm{~min}^{-1}$.

\subsection{Characteristics of MA powder}

The change in morphology of the MA powder with milling time was examined. The change in particle size of the MA powder with milling time at $200 \mathrm{~min}^{-1}$ is shown in Fig. 6. The powder particles agglomerate together and become larger in diameter with an increase in milling time. The particles at $360 \mathrm{ks}$ coarsen because of agglomeration and cold welding during MA process. The milling time to agglomerate and cold-weld the powder became shorter with an increase in rotational speed. In the case of higher rotational speed of $500 \mathrm{~min}^{-1}$, the MA powder coarsened in a short milling time of $36 \mathrm{ks}$. The change in particle size with milling time is shown in Fig. 7. The peak values of the distribution in particle diameter are given in this figure. In both cases of methanol and no process control agents, the particle size becomes smaller with an increase in milling time. This result means that the agglomerated powder becomes finer by mechanical grinding. In the case of methanol, the particle size is finer at $72 \mathrm{ks}$, but in the case of no process control agents, the particle size is finer at $360 \mathrm{ks}$. This means that, in the case of no process control agents, the powder cold-welds onto milling balls and a wall of vial and then grinds mechanically. ${ }^{14)}$ Shiga et al. ${ }^{15)}$ reported that the powder by mechanical grinding is finer in particle size than that by MA. This result is consistent with our experimental one.

Figure 8 shows the change in microstructure of the MA powder with milling time. The powder particles are laminated by plastic deformation and cold welding, and the

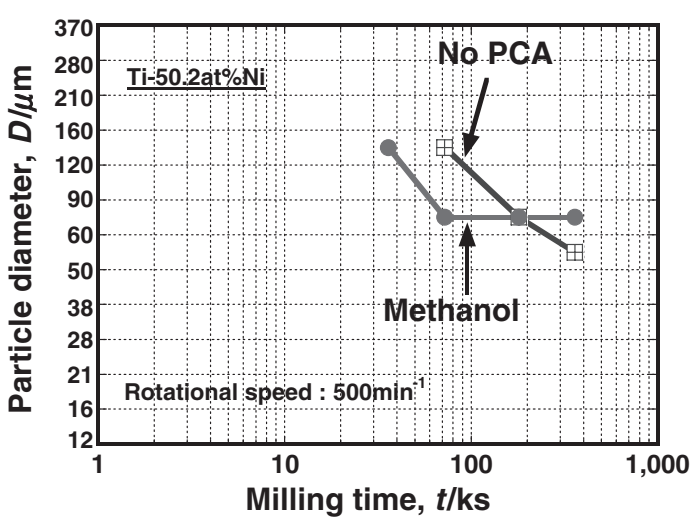

Fig. 7 Change in particle size with milling time.

thickness of the layer becomes thinner with an increase in milling time. Figure 9 gives the SEM images and the results of EDX analysis of the mechanically alloyed at 200 and $400 \mathrm{~min}^{-1}$ for $36 \mathrm{ks}$. In the case of rotational speed of $200 \mathrm{~min}^{-1}$, the layered structure of $\mathrm{Ti}$ and $\mathrm{Ni}$ powders is able to be observed clearly at $36 \mathrm{ks}$, and this suggests that the alloying of powder mixture was not enough proceeded. On the other hand, in the case of $400 \mathrm{~min}^{-1}$, Ti and Ni elements distribute uniformly in a powder particle, and this suggests that the alloying of powder was enough proceeded.

To confirm the state of alloying of powder mixture, XRD analysis was performed. Figure 10 shows the XRD patterns 
(a) $36 \mathrm{ks}$

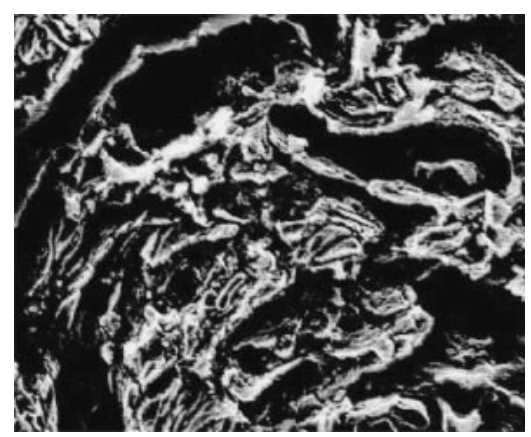

(c) $180 \mathrm{ks}$

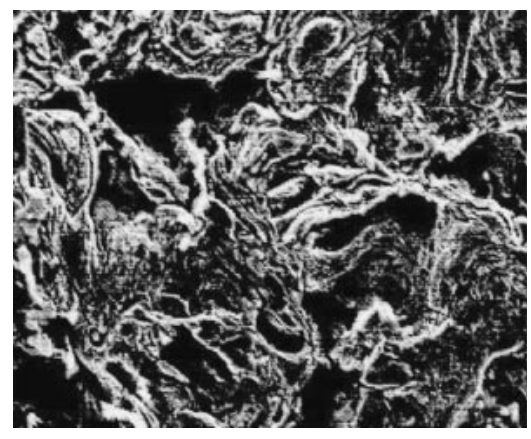

(b) $72 \mathrm{ks}$

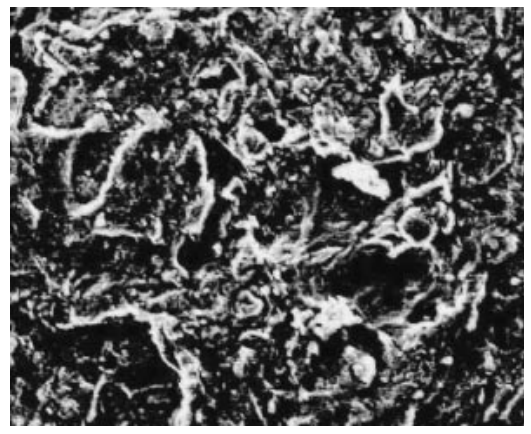

(d) $360 \mathrm{ks}$
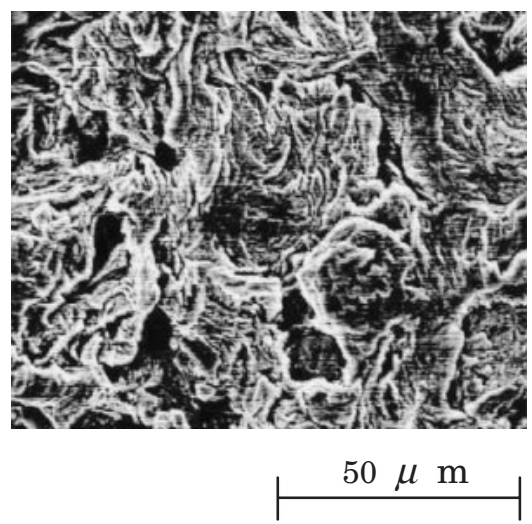

Fig. 8 Change in microstructure of the MA powder with milling time at $200 \mathrm{~min}^{-1}$.

of the MA powder and the V-blended powder. In these figures, the peaks are those of $\mathrm{Ti}$ and $\mathrm{Ni}$ powders. In the case of $200 \mathrm{~min}^{-1}$, the height of peaks of $\mathrm{Ti}$ and $\mathrm{Ni}$ powders lowers with increasing milling time, and these peaks vanish completely at $360 \mathrm{ks}$. But in the case of $400 \mathrm{~min}^{-1}$, as shown in the results of EDX analysis, the peaks of $\mathrm{Ti}$ and $\mathrm{Ni}$ powders already vanish at $36 \mathrm{ks}$, and this means that the powder particles achieve an amorphous state.

\subsection{Characteristics of sintered compacts of MA powder}

The MA powder was sintered, and the microstructures of the sintered alloy were examined. The methanol that can retain high recovery percentage and lower contamination of the MA powder was employed as a process control agent. Figure 11 shows the optical microstructures of the sintered alloy of the MA powder fabricated at $200 \mathrm{~min}^{-1}$ for $360 \mathrm{ks}$ and the V-blended powder. In the case of the MA powder, the microstructure is inhomogeneous at a sintering temperature of $1123 \mathrm{~K}$, but it is homogeneous at 1173 and $1223 \mathrm{~K}$, and it is relatively similar to that of the wrought material. The microstructure of the sintered alloy of the V-blended powder is inhomogeneous and it is significantly different from that of the sintered alloy of the MA powder. But, larger pores can be observed in the sintered compacts of the MA powder.

Figure 12 shows the change in relative density of the sintered alloy of the MA powder with sintering temperature. The relative density of the sintered alloy of the MA powder fairly increases with elevating sintering temperature, but it is 93.4\% even at $1223 \mathrm{~K}$ and considerably lower than that of the sintered alloy of the V-blended powder. Thus, the microstructure of the sintered compacts of the MA powder is obviously finer and more homogeneous than that of the sintered alloy of the V-blended powder, but the density of the former is lower than that of the latter. This is probably because of the sinterability reduced due to larger MA powder particles in size and lower sintering temperature determined by referring to that of the sintered alloy of the V-blended powder as shown in the Ti-Ni phase diagram. ${ }^{16)}$

Figure 13 shows the XRD patterns of the sintered alloys of the MA powder and the V-blended powder. The peaks of TiNi phase of the sintered alloy of the MA powder are obviously higher than that of the sintered alloy of the Vblended powder. This is because the microstructures of the sintered alloy of the MA powder change easily due to an amorphous state of the MA powder. But, $\mathrm{Ti}_{2} \mathrm{Ni}$ and $\mathrm{TiNi}_{3}$ phases except TiNi phase exist slightly in the sintered alloy of the MA powder as well as the V-blended powder.

The transformation temperature of the alloy was measured using DSC. Figure 14 shows the DSC curve of the sintered alloy of the MA powder. The transformation temperatures of $A_{\mathrm{S}}$ and $A_{\mathrm{f}}$ are 355.4 and $365.2 \mathrm{~K}$, respectively. The transformation temperature of the sintered alloy of the MA powder is higher than that of the wrought material by about $30 \mathrm{~K}$ at the peak temperature. This suggests that Ni content became lower than that of the powder mixture. This reduction in $\mathrm{Ni}$ content is because of cold welding of $\mathrm{Ni}$ powder onto a wall of vial and milling balls due to ductility of $\mathrm{Ni}$ powder having fec structure. ${ }^{17)}$ Judging from this transformation 


\section{$200 \mathrm{~min}^{-1}$}

$400 \mathrm{~min}^{-1}$

(a) SEM
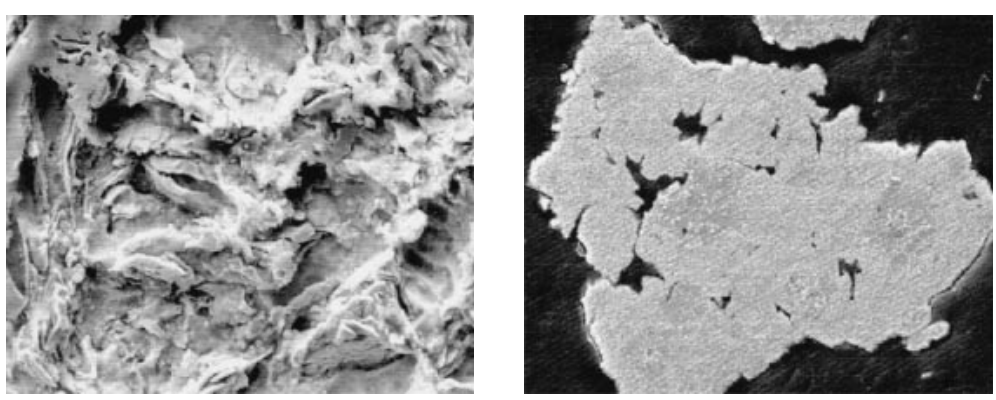

(b) $\mathrm{Ti} \mathrm{K} \alpha$
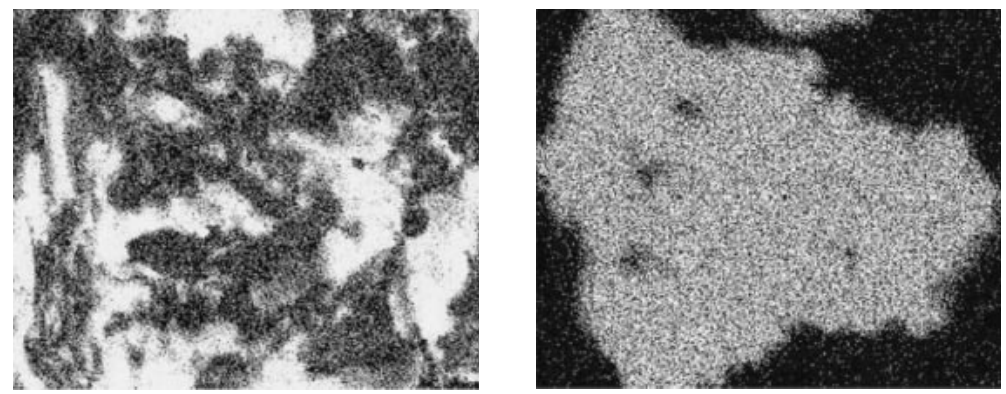

(c) $\mathrm{Ni} \mathrm{K} \alpha$
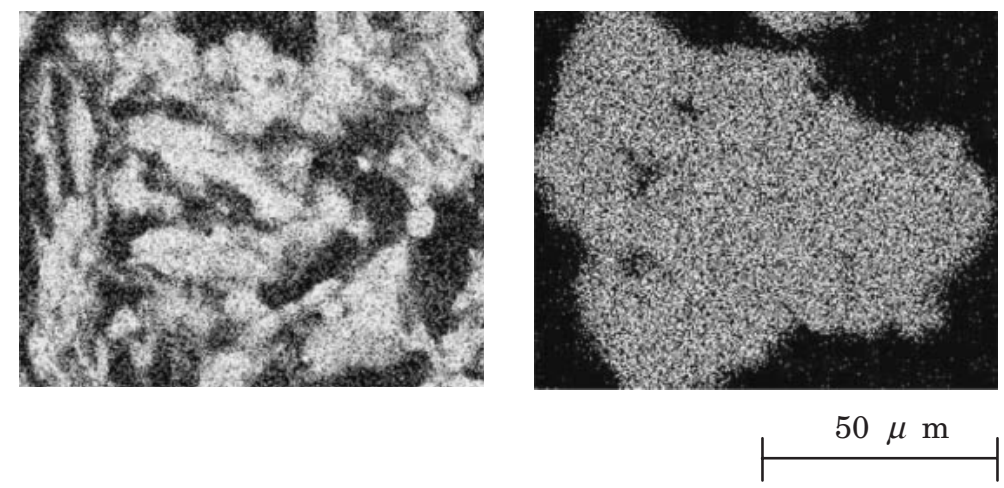

Fig. 9 SEM images and results of EDX analysis of the powder mechanically alloyed at 200 and $400 \mathrm{~min}^{-1}$ for $36 \mathrm{ks}$.

(a) $200 \mathrm{~min}^{-1}$

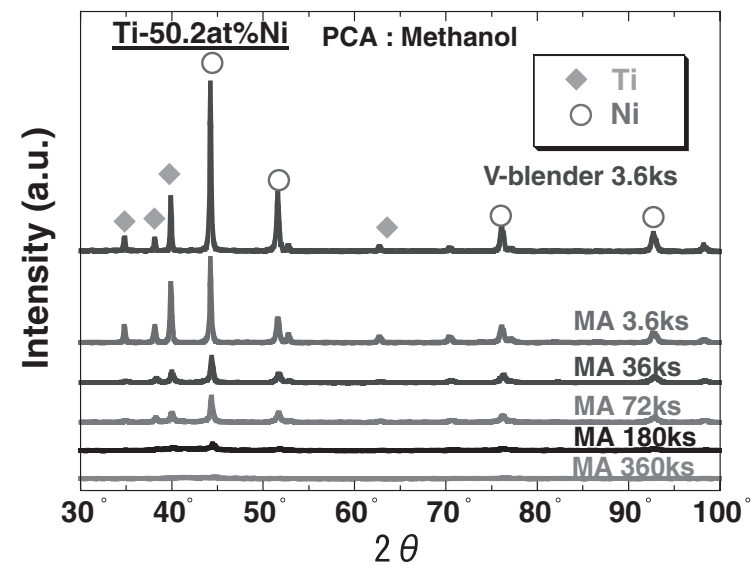

(b) $400 \mathrm{~min}^{-1}$

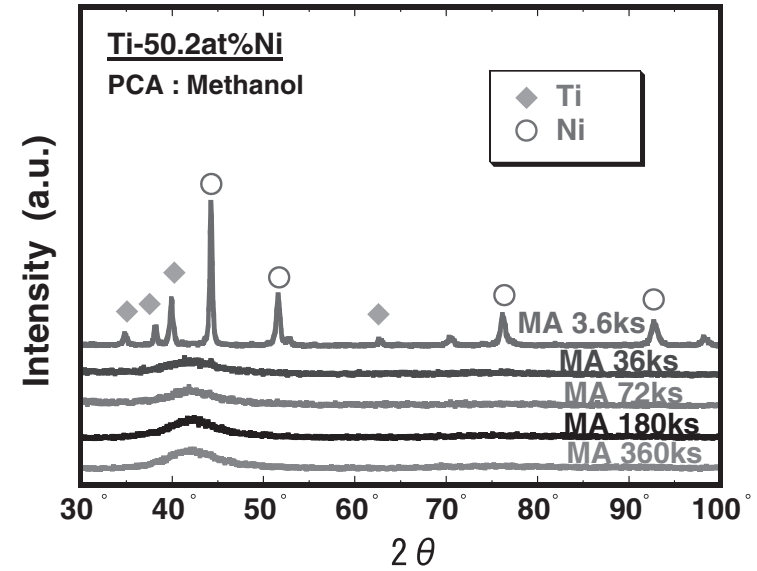

Fig. 10 X-ray diffraction patterns of the MA powder and the V-blended power. 
(a) MA powder, $1123 \mathrm{~K}$

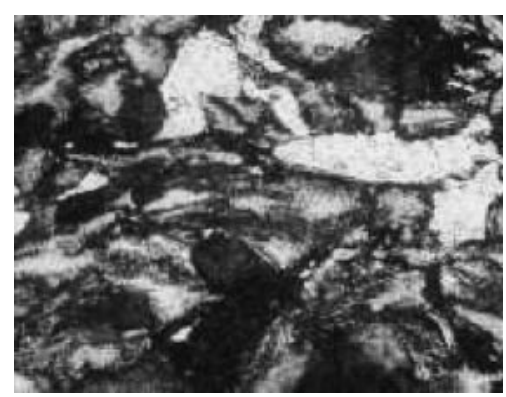

(c) MA powder, $1223 \mathrm{~K}$

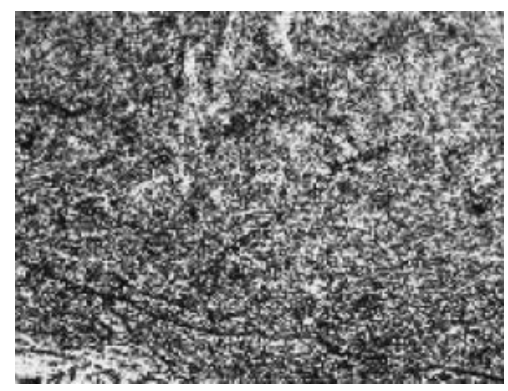

(b) MA powder, $1173 \mathrm{~K}$

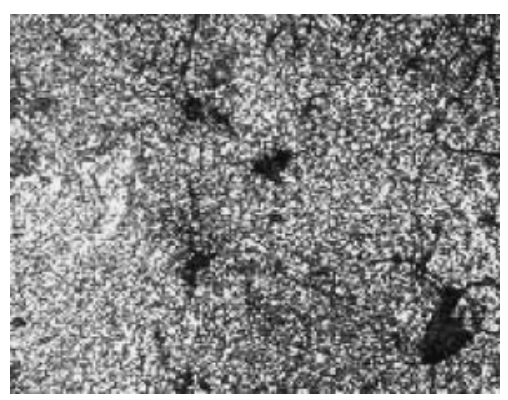

(d) V-blended powder, $1123 \mathrm{~K}$

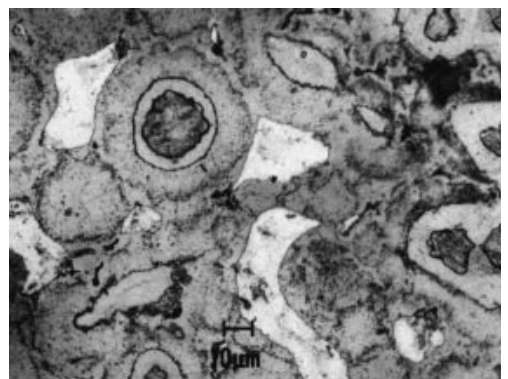

$50 \mu \mathrm{m}$

Fig. 11 Optical microstructures of the sintered alloy of the MA powder and the V-blended powder.

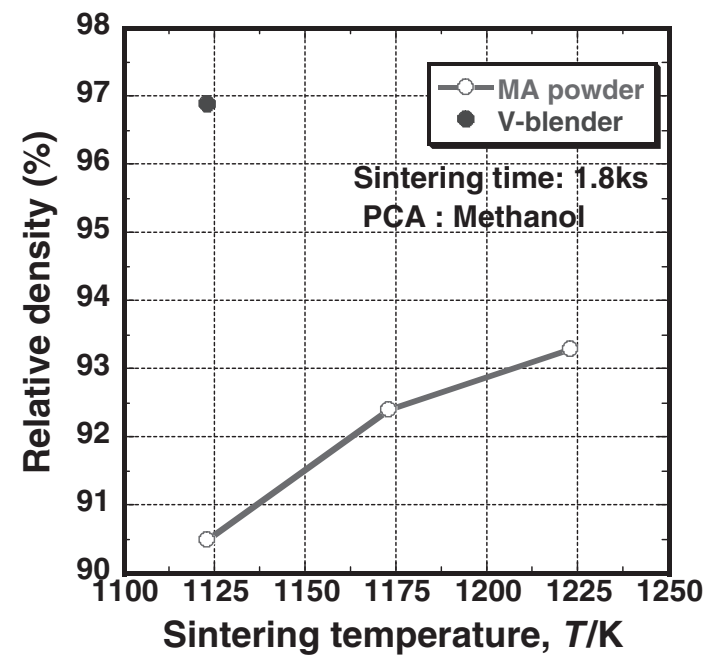

Fig. 12 Change in relative density of the sintered alloy of the MA powder with sintering temperature.

temperature, the alloy fabricated corresponds to $\mathrm{Ti}-50$ at $\%$ $\mathrm{Ni}$.

\section{Conclusions}

In this research, we investigated the fabrication conditions, such as process control agents, rotational speed and milling time, which are significant to fabricate the $\mathrm{Ti}-\mathrm{Ni}$ shape memory alloy powder by MA process. Also, we examined the powder characteristics and the microstructures and shape memory properties of the sintered alloy of the MA powder. The results obtained are as follows:

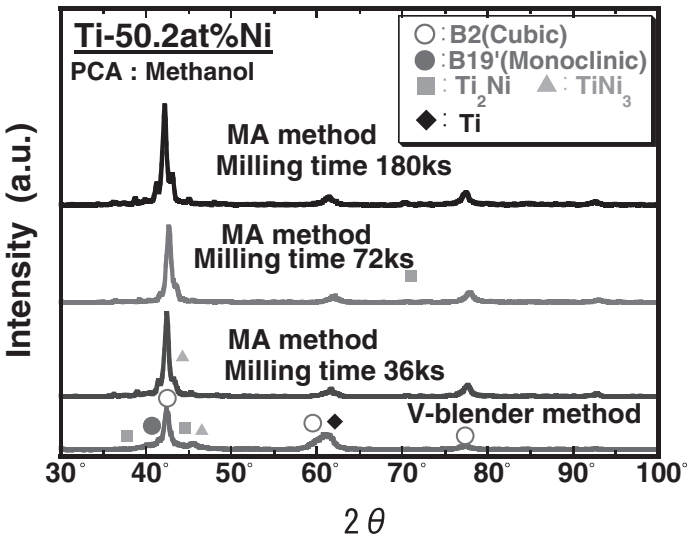

Fig. 13 X-ray diffraction patterns of the sintered alloys of the MA powder and the V-blended powder.

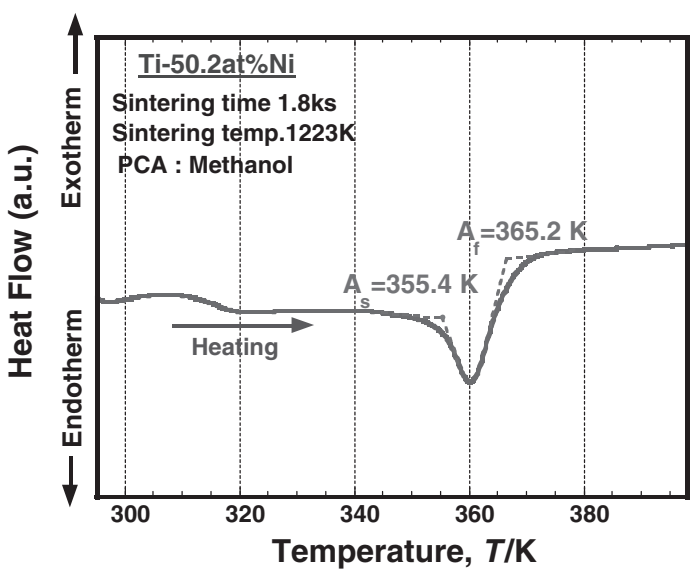

Fig. 14 DSC curve of the sintered alloy of the MA powder. 
(1) The oxygen content of the MA powder using methanol as a process control agent is much lower than that of the MA powder using water.

(2) The higher the rotational speed, the higher the carbon content of the MA powder, while the lower the oxygen content of the MA powder.

(3) The carbon content of the MA powder hardly increases with an increase in milling time, but the oxygen content fairly increases.

(4) The rotational speed considerably affects on the microstructure of the MA powder. In the case of $200 \mathrm{~min}^{-1}$ it changes to an amorphous state at $360 \mathrm{ks}$, but in the case of more than $300 \mathrm{~min}^{-1}$ it changes at only $36 \mathrm{ks}$.

(5) The density of the sintered alloy of the MA powder is considerably lower than that of the sintered alloy of the $\mathrm{V}$-blended powder, but the microstructure of the former becomes finer and more homogeneous and is similar to that of the wrought material.

(6) It is found from the measurement of the transformation temperature of the sintered alloy of the MA powder using DSC that the alloy has shape memory characteristics, and the transformation temperatures are higher than those of the sintered alloy of the V-blended powder due to waste of Ni powder.

\section{REFERENCES}

1) M. Otaguchi, Y. Kaieda, N. Oguro, S. Shite and T. Oie: J. Jpn. Inst. Met. 54 (1990) 214-223.
2) H. Kyogoku, T. Hatakeyama, F. Yoshida, S. Komatsu and T. Sakuma: Proc. 1998 Powder Metallurgy World Congress (Granada), Vol. 5, (EPMA, 1998) pp. 431-436.

3) H. Kyogoku, T. Tanbo, S. Komatsu, T. Watanabe, F. Yoshida, T. Sakuma and U. Iwata: Advances in Powder Metallurgy \& Particulate Materials-2000, (MPIF, Princeton, 2000) pp. 9.45-9.56.

4) H. Kyogoku, F. Yoshida and T. Sakuma: Int. J. Materials Processing Technology (CD-ROM), Vol. 117, Issue3, (2001).

5) H. Kyogoku, T. Tanbo, M. Yokota, S. Komatsu, F. Yoshida, T. Sakuma and U. Iwata: Advances in Powder Metallurgy \& Particulate Materials-2001, (MPIF, Princeton, 2001) pp. 7.1-7.9.

6) H. Esaki and M. Tokizane: Mater. Sci. Forum 88-90 (1992) 625-630.

7) T. H. Nam, I. S. Ahn, S. G. Hur and S. H. Kang: Advances in Powder Metallurgy \& Particulate Materials-1999, (MPIF, Princeton, 1999) pp. 12.95-12.105.

8) K. Kobayashi, A. Matsumoto, K. Ozaki, A. Sugiyama and T. Nishio: J. Jpn. Inst. Met. 63 (1999) 1161-1164.

9) M. Otake, K. Isobe, T. Kosugi, K. Tsuchiya and M. Umemoto: J. Jpn. Soc. Powder Powder Metall. 46 (1999) 746-751.

10) P. S. Goodwin and C. M. Ward-Close: Mater. Sci. Forum 179-181 (1995) 414-418.

11) P. S. Goodwin, T. M. T. Hinder, A. Wisbey and C. M. Ward-Close: Mater. Sci. Forum 269-272 (1998) 53-62.

12) P. S. Gilman and J. S. Benjamin: Annu. Rev. Mater. Sci. 13 (1983) 279-300.

13) K. Kusaka, T. Khono, T. Kondo and A. Horata: J. Jpn. Soc. Powder Powder Metall. 42 (1995) 383-387.

14) L. Lu and M. O. Lai: Mechanical Alloying, (Kluwer Academic Publishers, Boston, 1998) p. 26.

15) S. Shiga, T. Norimatsu, T. Itsukaichi, M. Umemoto and I. Okane: J. Jpn. Soc. Powder Powder Metall. 38 (1991) 976-980.

16) J. L. Murray: Binary Alloy Phase Diagram, 2nd ed., Vol. 3, Massalski, T. B. ed., (ASM Intern., Materials Park, 1996) p. 2875.

17) J. S. Benjamin: Mater. Sci. Forum 88-90 (1992) 1-17. 